\title{
Dificuldades de utilização do preservativo masculino entre homens e mulheres: uma experiência de rodas de conversa
}

Denise Alves Guimarães. Universidade Federal de São João Del Rei

Vanessa Cristina de Paiva Oliveira. Universidade Federal de São João Del Rei

Leandro Cesar da Silva. Hospital MedCenter, Patrocínio/MG

Cândida Amélia Marinho de Oliveira. Maternidade Odete Valadares, Belo Horizonte/MG

Rânia Andrade Lima. Hospital Fundação Ouro Branco (FOB)/MG

Carlos Alberto Pegolo da Gama. Universidade Federal de São João Del Rei

\section{Resumo}

Nesse artigo, identificamos e analisamos as dificuldades de utilização do preservativo masculino entre 153 pessoas, (59 homens e 94 mulheres), durante pesquisa qualitativa, em município de médio porte do centro-oeste de Minas Gerais, Brasil. Foi utilizada a metodologia de roda de conversa e, por meio da análise do material, observou-se baixa adesão ao uso de preservativo pelos sujeitos participantes da pesquisa, devido tanto a percepções relacionadas ao pensamento mágico, quanto a relações de gênero e o arcabouço sociocultural dos sujeitos. Por fim, sugere-se que as políticas públicas de prevenção ao agravamento da epidemia de HIV/aids sejam elaboradas com base em metodologias participativas de educação em saúde, que promovam o empoderamento dos sujeitos, de modo que eles possam não somente acessar as informações acerca dos modos de prevenção, mas que também tenham autonomia crítica para escolherem e negociarem suas estratégias preventivas.

Palavras-chave: HIV; preservativo masculino; prevenção da aids.

\begin{abstract}
Difficulties associated with condom use among men and women: a talking circle experience. In this article, we identified and analyzed male condom use difficulties among 153 people, (59 men and 94 women) during a qualitative study in a medium-sized municipality in the Midwest of Minas Gerais, Brazil, using the talking circle methodology. Through the analysis of the material, low adherence to condom use was observed by the subjects participating in the research, due to perceptions related to magical thinking, gender relations as well as the sociocultural framework of the subjects. Finally, it is suggested that public policies which aim to prevent the worsening of the HIV/AIDS epidemic should be elaborated considering participative health education methodologies which promote the subjects' empowerment, so that they can not only access the information about prevention modes, but also have critical autonomy to choose and negotiate their preventive strategies.
\end{abstract}

Keywords: HIV; condom; AIDS prevention.

\section{Resumen}

Dificultades en el uso del condón masculino entre hombres y mujeres: una experiencia de ruedas de conversación. En este artículo, identificamos y analizamos las dificultades de uso del condón entre 153 personas ( 59 hombres y 94 mujeres) durante una investigación cualitativa, en un municipio de mediano porte del centro-oeste de Minas Gerais, Brasil, valiendo-nos de la metodología de rueda de conversación. Por medio del análisis del material, se observó baja adhesión al uso de preservativo por los sujetos participantes de la investigación, debido tanto a percepciones relacionadas al pensamiento mágico, en cuanto a relaciones de género y el marco sociocultural de los sujetos. Por último, se sugiere que las políticas públicas de prevención al agravamiento de la epidemia de $\mathrm{VIH} /$ sida sean elaboradas con base en metodologías participativas de educación en salud, que promuevan el empoderamiento de los sujetos, de modo que ellos puedan no sólo acceder a las información sobre los modos de prevención, pero que también tengan autonomía crítica para elegir y negociar sus estrategias preventivas.

Palabras clave: VIH; condón; prevención del SIDA. 
A epidemia de HIV/aids está em sua quarta década e, no mundo, há aproximadamente 37,9 milhões de pessoas vivendo com HIV (PVHIV), sendo cerca de 900.000 delas no Brasil (Ministério da Saúde [MS], 2018a; Joint United Nations Programme on HIV/ AIDS [Unaids], 2019a). Estima-se queda global de 16\% no número de novas infecções pelo vírus e de $33 \%$ da mortalidade relacionada à aids no período de 2010 a 2018. Na contramão do contexto mundial, o Brasil registrou aumento de $21 \%$ do número de infecções por HIV nesse mesmo período (Unaids, 2019a), e a região Sudeste concentrou maior número de notificações de casos pelo Sistema de Informação de Agravos de Notificação (SINAN), com 47,4\% entre 2007 e 2018, e $40 \%$ de óbitos por HIV/aids como causa básica (MS, 2018b).

A população feminina corresponde a mais da metade das PVHIV, havendo 19,6 milhões de mulheres e meninas infectadas no mundo e 307 mil no Brasil (MS, 2018a; Unaids, 2019b). Enquanto, em algumas áreas, os números demonstram aumento expressivo dos casos de aids entre pessoas do gênero feminino; no Brasil, desde 2009, percebe-se uma tendência inversa. De acordo com dados do Ministério da Saúde, a razão de sexo foi de 2,3:1 em 2018 (MS, 2018b). De qualquer forma, mulheres estão mais vulneráveis à infecção por HIV por diversos motivos: aspectos fisiológicos, menor acesso a serviços de saúde, dificuldade de negociação de práticas sexuais seguras, violência doméstica, dificuldades na tomada de decisões sobre sua própria saúde, e por outras questões também ligadas à desigualdade de gênero (Jewkes, 2010; Unaids, 2016). Esses problemas são maiores entre profissionais do sexo, mulheres trans e travestis e usuárias de drogas injetáveis, que estão mais submetidas à estigmatização, discriminação, violência e obstáculos legais que dificultam comportamentos preventivos e adesão ao tratamento, se houver diagnóstico (The Foundation for AIDS Research [amfAR], 2015). Junto a gays, homens que fazem sexo com homens, e pessoas privadas de liberdade, esses grupos compõem populações-chave, que perfizeram $65 \%$ das novas infecções por HIV na América Latina em 2018 (Unaids, 2019b).

Historicamente, a resposta brasileira à aids é considerada um modelo para o mundo, em grande medida devido à participação incisiva da sociedade civil na formulação das políticas públicas de combate à epidemia, paralelamente à defesa do regime democrático, do combate à discriminação e aos processos geradores de exclusão, violência social e estigma (Parker, 2015). Toda a mobilização em relação ao enfrentamento da doença guarda uma relação próxima com o movimento que reivindicou a estruturação do Sistema Único de Saúde (SUS), cuja pauta se baseava no princípio da saúde como direito de todos e dever do Estado, o que permite também que prevenção e acesso a insumos sejam entendidos como direitos (Nogueira \& Pires, 2004). Assim, uma abordagem adequada requer que se pense o campo da prevenção a partir de uma conjugação de diferentes estratégias, o que tem sido definido, pela UNAIDS, como prevenção combinada. Ela implica a conciliação de direitos, evidências e a base comunitária na promoção de intervenções biomédicas, comportamentais e estruturais criadas para atender à demanda de pessoas e comunidades específicas, sem que haja hierarquização ou predomínio de uma modalidade preventiva sobre a outra, e respeitando-se, sempre, a autonomia e singularidade dos sujeitos (Unaids, 2010). Em consonância com essa proposta, o Ministério da Saúde buscou promover a integração dos diferentes níveis de atenção, de forma a qualificar as ações de IST e HIV em todas as Redes de Atenção à Saúde (Adamy, Casimiro, \& Benzaken, 2018).

No entanto, apesar dos esforços e conquistas históricos, percebe-se que, de modo crescente, a resposta brasileira tem sido orientada pela ótica biomédica, que guarda relações com um raciocínio de ordem liberal, e que propõe modelos de prevenção focados no indivíduo enquanto consumidor de medicamentos. Essa lógica também se associa a outras tendências crescentes no debate público brasileiro, apoiadas em percepções imbuídas de preconceito e medo em relação a questões sobre sexualidade, impulsionadas por um discurso fundamentalista religioso e hiperconservador. A combinação de neoliberalismo e conservadorismo moral tem como resultado, em termos de políticas públicas de aids, a imposição do paradigma biomédico sobre as intervenções coletivas e a resposta social, culminando na piora da qualidade de vida das PVHA, em especial os mais vulneráveis (Marafon, 2018; Parker, 2015; Rios, 2018). Além disso, nos últimos anos, tem-se delineado um panorama ainda mais ameaçador ao Programa Brasileiro de Aids. A aprovação da Emenda Constitucional 95, em 15 de dezembro de 2016, agrava ainda mais o cenário de subfinanciamento do SUS, e predispõe a acentuação de sua fragmentação, redução dos investimentos e queda na qualidade e segurança dos serviços (Noronha, Noronha, Pereira, \& Costa, 2018). Mais recentemente,

Estudos de Psicologia, 24(1), janeiro a março de 2019, 21-31 
o Decreto $N^{\circ} 9.795$, de 17 de Maio de 2019, subsumiu o Departamento de IST, AIDS e Hepatites Virais ao novo "Departamento de Doenças de Condições Crônicas e Infecções Sexualmente Transmissíveis", colocando, sob mesma tutela, HIV/aids, as diversas IST, hepatites virais e outras condições crônicas, como tuberculose e hanseníase. Esse decreto foi recebido por diversos agentes envolvidos no movimento nacional de luta contra a aids como "o Fim do Programa Brasileiro de Aids", a partir de um desmantelamento do programa e da invisibilidade das pessoas vivendo e convivendo com HIV. ("Política de morte: o fim do departamento de AIDS", 2019).

Nessa perspectiva, considerando o uso de preservativo masculino como uma tecnologia biomédica que, todavia, deve-se articular a estratégias de intervenção também estruturais e comportamentais, o presente artigo tem por objetivo identificar e analisar as dificuldades de utilização do preservativo masculino por homens e mulheres. Destaca-se a pertinência e relevância do estudo, considerando-se ainda a escassez de pesquisas relacionadas à prevenção do HIV/aids na região estudada.

\section{Método}

Foi conduzido estudo exploratório (Goulart, 2002), de caráter qualitativo (Minayo, 2008), entre novembro de 2014 e fevereiro de 2016, em município de médio porte do centro-oeste de Minas Gerais, Brasil, com 153 pessoas, sendo 59 homens e 94 mulheres. Este estudo nasce das ações desenvolvidas em projeto de extensão em interface com a pesquisa, intitulado "Educação em saúde: sexualidade e prevenção de DST/ aids", financiado pelo PRO/PET SAÚDE e pela FAPEMIG Fundação de Amparo à Pesquisa do Estado de Minas Gerais e representa um ensaio reflexivo a partir de experiências desenvolvidas em rodas de conversa.

Foi utilizada metodologia de roda de conversa, caracterizada como uma metodologia participativa cujo intuito é a criação de condições dialógicas entre os participantes envolvidos, por meio de um ambiente em que se privilegiem a escuta e a circulação da palavra, de modo que os temas abordados sejam partilhados e refletidos. Buscou-se incentivar a participação e implicação dos sujeitos nas discussões propostas em grupo, possibilitando a desconstrução e reconstrução de conceitos, práticas cotidianas e formas de pensar a realidade (Souza, 2017). A organização e condução dessa metodologia estão ancoradas nos referenciais da pedagogia crítica de Paulo Freire (Freire, 2002) e da psicologia social sobre a intervenção psicossocial e processo grupal, pertinentes às atividades de educação em saúde (Secretaria Geral da Presidência da República, 2014). Nessa perspectiva, os pesquisadores deixam de ser detentores da informação para serem mediadores do saber, a partir de uma metodologia participativa de educação em saúde na qual os participantes são convidados à discussão a partir de temas geradores e dinâmicas desenvolvidas pelos moderadores (Afonso, 2006; Afonso \& Abade, 2008).

Foram realizadas três rodas de conversa com cada grupo participante, tendo sido abordados 10 grupos, perfazendo um total de 30 encontros e cada encontro tinha em média a duração de 2 horas e a participação de aproximadamente 15 participantes. Os grupos foram formados em instituições que aceitaram participar das atividades de extensão e pesquisa, sendo uma instituição de Educação de Jovens e Adultos (EJA), três Instituições de Assistência Social, uma Instituição religiosa, uma Instituição de Ensino superior e quatro Instituições de saúde. As instituições convidadas a participar estavam vinculadas às regiões sanitárias do município que foram alvo das ações previstas no projeto e definidas em parceria com a Secretaria Municipal de Saúde. Nessas instituições foram convidados a participar seus trabalhadores e usuários.

Por se tratar de um tema tabu e das relações de maior proximidade entre os participantes que habitavam uma mesma região do município, houve dificuldades na abordagem dos participantes e na consequente organização dos grupos. As pessoas abordadas relataram medo em discutir os temas e medo de se exporem. Por esse motivo, os pesquisadores optaram por não realizar a gravação das discussões e no processo de recrutamento de participantes era explicado que os registros das discussões seriam feitos por escrito por observadores treinados.

Os grupos organizados possuíam composição heterogênea em relação ao sexo e faixa etária, mas possuíam homogeneidade em relação ao grau de escolaridade e nível hierárquico/relações de poder entre os participantes. Nesse sentido, para a organização das discussões optou-se por não colocar em um mesmo grupo professores e alunos; trabalhadores e suas chefias ou supervisores; profissionais e usuários, com o objetivo de evitar constrangimentos em decorrência das relações de poder entre participantes de uma mesma instituição. As principais características que uniam os participantes dos grupos estavam relacionadas, portanto, ao pertencimento e/ou participação nas instituições abordadas e 
ao desejo dos mesmos em envolver-se na discussão de temas relacionados à sexualidade.

As rodas de conversa abordaram temas vinculados à sexualidade e prevenção de IST e aids, foram coordenadas por dois moderadores (um homem e uma mulher) que propunham e mediavam as discussões e dois observadores (um homem e uma mulher) que registravam as falas e as reações dos participantes com relação à discussão. Nas rodas de conversa os moderadores apresentaram perguntas disparadoras ou propunham questões relacionadas aos temas e os participantes foram convidados a expressarem livremente suas opiniões. Vale ressaltar que a roda de conversa não diz respeito a uma disposição física em roda, nem apenas um espaço onde as pessoas relatam experiências, mas sim uma oportunidade para a produção de sentidos que, compreendidos à luz da pedagogia crítica e educação popular de Paulo Freire, refletem conjuntos de conflitos, possibilidades e condicionantes. As falas dos participantes expressam, portanto, modos de vida (Souza, 2017).

O registro das falas foi o material considerado para o desenvolvimento desse estudo e a análise das mesmas considerou o referencial de análise de conteúdo (Bardin, 2011). As falas foram agrupadas considerando-se os temas que emergiram livremente nas discussões dos grupos e posteriormente foi feita a definição das categorias que melhor reuniam um conjunto de núcleos de sentido. As categorias que emergiram da análise das falas foram: 1) uso de preservativo, relações de gênero e ideais de amor romântico; 2) percepção sobre o preservativo e sua utilização; 3) conhecimentos sobre preservativos e IST/aids e as mudanças de comportamento e percepções relacionadas às práticas sexuais. Após a análise, os resultados foram discutidos à luz da literatura científica sobre o tema; foram utilizadas falas para ilustrar as discussões e adotou-se a seguinte codificação após a apresentação das falas: a letra S seguida do número que correspondente ao participante; idade e as siglas referentes à escolaridade (ESC - Ensino Superior Completo; ESI - Ensino Superior Incompleto; EM - Ensino Médio e EF - Ensino Fundamental). A pesquisa foi aprovada por Comitê de Ética em Pesquisa sob parecer 131.321 de 07/11/2012 e foram resguardados todos os princípios éticos.

\section{Resultados e discussão}

Os grupos eram compostos por homens e mulheres, em diferentes instituições públicas e privadas e houve uma pequena variação em relação aos participantes desses grupos ao longo dos encontros. Cabe ressaltar que nem todos os participantes se sentiram à vontade para expressarem suas opiniões, especialmente os participantes do sexo masculino, acerca dos temas propostos, mas mantiveram-se vinculados às atividades propostas e muitos deles avaliaram de forma positiva sua participação. Todos os participantes eram residentes do município em que a pesquisa foi realizada; com idades que variavam entre 18 e 57 anos. A escolaridade variou entre Ensino Fundamental (36 mulheres e 21 homens); Ensino Médio (14 mulheres e 20 homens); Ensino Superior Incompleto (32 mulheres e 13 homens) e Ensino Superior Completo (12 mulheres e cinco homens). Não foi conduzida investigação sobre renda; ocupação/trabalho atual; orientação sexual; vinculação religiosa; ou condições de saúde. Considerou-se a declaração dos participantes sobre situação conjugal e número de parceiros.

Em seu conjunto, os resultados demonstram a persistência de dificuldades relacionadas ao uso do preservativo entre mulheres e homens residentes em uma região específica do Brasil em que não há abundância de dados similares.

a) Uso do preservativo, relações de gênero e ideais de amor romântico: Esta categoria busca apresentar e discutir a questão da hierarquia das relações de gênero como organizadora das percepções e práticas dos participantes acerca do uso do preservativo; da distribuição de responsabilidades quanto ao uso do mesmo; das percepções de proteção contra IST/aids vinculadas aos ideais de amor romântico, suposição de fidelidade entre os parceiros e confiança vinculada às relações estáveis e de maior tempo de duração.

As falas dos participantes das rodas de conversa corroboram estudos nacionais que apontam que a desigualdade das relações de gênero se apresenta como norteadora das práticas sexuais entre homens e mulheres, aumentando a situação de vulnerabilidade por dificultar o uso de preservativos. (Andrade et al, 2015; Antunes, Peres, Paiva, Stall, \& Hearst, 2002; Seffner \& Parker, 2015; Silva, 2012). As falas dos participantes demonstraram submissão das mulheres e repressão feminina em relação aos referenciais sociais que sustentam maior poder do homem nas práticas sexuais, bem como o baixo poder de negociação das mulheres com seus parceiros em relação ao uso de preservativo, apontando para os sentimentos de impotência e submissão de mulheres em relação ao desejo do parceiro

Estudos de Psicologia, 24(1), janeiro a março de 2019, 21-31 
(Andrade et al, 2015; Antunes et al, 2002; Silva, 2012). Nenhum homem das diferentes rodas de conversa realizadas se manifestou em relação a essa questão e as falas de mulheres a seguir demonstram a submissão feminina aos referenciais de sexualidade masculinos:

"O homem manda na relação e por isso não é fácil usar a camisinha ou até sugerir seu uso." (S2, F, 35, EM)

"É complicado usar camisinha no relacionamento porque o marido não gosta de usar." (S30, F, 30, EF)

"Meninas têm medo e vergonha de pegar preservativo." (S53, F, 35, ESC)

Entretanto, também apareceram falas de homens e mulheres que faziam referência à distribuição de responsabilidades e diálogo entre os casais em relação ao uso do preservativo:

"Acho que tem que usar, mas tem as questões conjugais. Os dois têm que querer." (38, F, 31, EF)

"Tudo depende dos acordos morais entre os casais. O meu acordo com meu atual parceiro é o seguinte: se um de nós tiver algum relacionamento extraconjugal, vai chegar e dizer para o outro, para fazer o que for preciso." (S51, F, 48, ESC)

"A camisinha não precisa ser uma obrigação só do homem. O homem não gosta. A mulher, mesmo que seja um incômodo pra ela, ela usa se for para um bem geral." (S54, M, 45, ESC)

Nas discussões das rodas, destaca-se que o maior tempo de relacionamento entre parceiros foi apontado como um fator que se opõe ao uso do preservativo. Pesquisas apontam que o maior tempo de união estável e o baixo nível de escolaridade colocam as mulheres em situação de vulnerabilidade para IST e aids, pela predominância de ideias apoiadas em construções sociais e culturais que demarcam subordinação das mulheres aos homens e pelas informações divulgadas, sobretudo pela mídia, no início da epidemia de que mulheres estariam protegidas do HIV/aids, por não fazerem parte dos chamados "grupos de risco" (Andrade et. al. 2015; Manuel, 2009; Rodrigues, Paiva, Oliveira, \& Nóbrega, 2012; Silva, 2012; Tura, 2005). Além disso, estudos apontam que homens e mulheres envolvidos em parcerias fixas, são os que menos se previnem contra os riscos de transmissão das IST e aids e menos utilizam preservativo (Aboim, 2012; Gutierrez et. al., 2019). Especialmente as discussões de Bacchini, (2017) destacam que o ideal de amor romântico pode criar para algumas mulheres uma ilusão na qual podem se colocar em situação de vulnerabilidade frente ao HIV/aids por sentirem que o amor as protege dos males da existência. O componente de irracionalidade presente na face idealizada do amor é apontado como importante fator que coloca mulheres em situação de vulnerabilidade pela total entrega ao outro.

As falas a seguir demonstram como o tempo de relacionamento e a confiança no parceiro são percebidos pelos sujeitos como fator protetivo em relação às IST e aids:

"Quem é casado não precisa usar camisinha, namorados tem que usar." (S1, F, 31, EM)

"Se eu desconfiar que meu marido me trai, não vou mais querer transar com ele." (S28, F, 31, EF)

"A partir do momento que você tá com o parceiro, e confia você não precisa usar não, você está há 10 anos com o seu marido e vai usar camisinha?" (S75, F, 32, EM)

"Aí eu estou há 3 anos com a pessoa eu garanto, dá para saber quando a pessoa mente para mim. Eu estou usando. Quando der 3 anos de namoro eu não vou usar não." (S76, M, 27, EM)

"Com namorada não, depende, tem que confiar." (S108, M, 19, EF)

"No meu caso não acho necessário. Sou casado, confio." (S109, M, 32, EF)

Percebe-se que a discussão sobre a utilização do preservativo entre os casais coloca em xeque a confiança presente na relação, construída e apoiada na ideia de fidelidade entre os parceiros, mesmo que essas questões não tenham sido abertamente discutidas e negociadas. Os participantes das rodas, de forma geral, declararam não conversar com seus parceiros sobre a importância do uso de preservativo; sobre práticas sexuais que exponham ao risco de contaminação às IST/aids; sobre a possibilidade de relações extraconjugais ou práticas sexuais com outros parceiros e sobre a realização de exames para conhecimento do estado sorológico.

Introduzir na relação a discussão sobre os motivos para a utilização ou não utilização do 
preservativo acaba por colocar em pauta uma série de interrogações que normalmente não fazem parte da dinâmica do relacionamento dos casais que se apoiam no ideal de amor que protege e no ideal de fidelidade contido nas relações supostamente monogâmicas. Nesse sentido, as discussões desenvolvidas nas rodas foram compatíveis com outros estudos que apontam que tanto o casamento, quanto o tempo de relação entre os parceiros e a questão da confiança no relacionamento, à medida que representam indicativos de solidez do vínculo, criam uma ideia de proteção contra as IST/aids, assumida por homens e mulheres como um elemento que dispensa o uso do preservativo (Andrade et. al. 2015; Bacchini, 2017; Gutierrez et. al., 2019; Silva, 2012). Esse mecanismo, que faz com que os sujeitos se percebam em situação fora de risco, se expressa como um pensamento mágico que parece sustentar a crença ou aposta na falsa ideia de proteção, e estabelecer uma zona de segurança. Nesse sentido, o pensamento mágico tanto se relaciona à realização de desejos, quanto à prevenção de eventos problemáticos ou desagradáveis. Aparece como tentativa do sujeito de escapar das ansiedades e dos conflitos que se colocam do mundo externo e interno; como se o pensamento fosse capaz de controlar, explicar e alterar a realidade (Lindenmeyer \& Ceccarelli, 2012). O ideal de amor romântico, a relação estável e o casamento aparecem como exemplos de situações que criariam uma cerca de proteção e o perigo estaria depositado em estereótipos que em certa medida foram introduzidos no imaginário popular no início da epidemia como grupos de risco que seriam, por exemplo, os homossexuais, as prostitutas e as pessoas consideradas com comportamentos promíscuos (Ayres, 2002; Bacchini, 2017; Knauth, 1998; Paiva, 1999; Silva, 2012). No entanto, por mais que os participantes das rodas tenham manifestado sua adesão à ideia de proteção, que se expressa como um pensamento mágico, também anunciaram dúvidas em relação a essa crença ou aposta. Homens e mulheres relataram receio de que a discussão sobre o uso do preservativo não seria bem aceita pelo parceiro, caso pensassem em fazê-la e mencionaram dificuldades de introduzir essa discussão pelo receio de levantar as possibilidades de traição de ambos os lados, o que representaria a ruptura do pacto de confiança das relações supostamente monogâmicas. A questão da desconfiança na relação frente à proposta do uso do preservativo pode ser exemplificada nas falas a seguir:
"Se eu chegar em casa e pedir meu marido para
usar camisinha a partir de agora, ele iria estranhar
e poderia desconfiar que estou fazendo algo de errado." (S15, F, 25, ESI)

"Por mim eu usaria, mas o meu marido prefere não usar. Então imagino que se eu insistir em usar ele pensará que tenho um relacionamento fora." (S29, F, 48, EF)

"Se não desconfiar do marido tudo bem, mas se desconfia tem que usar se não o bicho pega." (S84, F, 30, EF)

"Se eu falar pra minha esposa para usar camisinha ela vai me colocar pra fora de casa. Porque fizemos exames e não temos nada. Se não for fiel tem que usar. Se ela pedir eu vou achar ruim." (S86, M, 26, EF)

Além disso, é possível identificar também na fala das mulheres e de um único homem, um aspecto de moral religiosa cristã que parece sustentar a crença de que existe uma relação indissociável entre casamento, confiança e fidelidade. Aparece também a crença de que a vinculação a uma relação estável, aos moldes religiosos, seria um fator de proteção em relação às IST e aids. Por outro lado, os comportamentos que não seguem esse padrão de moralidade e ideal de família e casamento seriam os que colocariam os indivíduos em situação de risco. Estar circunscrito à situação de inserção em uma família e em um casamento, por si só assumem caráter protetivos e são acompanhadas, portanto, por uma crença de invulnerabilidade em relação ao HIV/aids. A possiblidade de rompimento dessa invulnerabilidade, por meio de uma traição, é vista de maneira tão distante que muitas vezes a reação manifestada apontava para um argumento extremo de atentar contra a vida do parceiro, o que põe em cheque a moral cristã ancorada no mandamento de não atentar contra a vida. Alguns exemplos de falas nesse sentido:

"Eu acho que você tem que confiar, porque se não confiar não faz sentido estar casada." (S130, F, 30, EF)

"Camisinha não é 100\% segura. O que seria 100\% seguro é você encontrar um parceiro que não te traia. O que a igreja prega? É a fidelidade." (S52, M, 50, ES)

"Eu não uso, confio no meu namorado. Eu fui a primeira dele e ele o meu. Se ele me trair eu mato ele. Tomo anticoncepcional." (S14, F, 27, ESI) 
"Já avisei: se eu pegar alguma coisa eu te mato, resolvo na marra, eu mato primeiro." (S81, F, 50, EF)

Essa perspectiva pode ser encontrada em pessoas de diferentes idades e escolaridade. Parece haver um reconhecimento de que ocorreram avanços nas relações de gênero; no entanto, estes ainda situam-se no nível do discurso, sendo de difícil incorporação nas formas de avaliar e se posicionar diante das situações e práticas cotidianas. Demonstrando as contradições presentes na sociedade atual, a sexualidade parece continuar sendo tratada como um tabu e a superexposição da sexualidade presente na mídia e nos comportamentos das pessoas e grupos convivem, ao mesmo tempo, com a grande dificuldade de falar sobre ela e de avançar para uma situação não polarizada entre homens e mulheres.

Ao longo da história da epidemia, estudos apontam a complexidade a ser considerada para o planejamento de políticas e ações de educação em saúde que busquem combater o avanço da epidemia de HIV/aids e de outras IST entre homens e mulheres. Estudos apontam que essa complexidade está relacionada tanto às questões culturais, que apontam altas taxas de homens que mantêm relações sexuais desprotegidas por alegarem que isso interfere no prazer ou por ferir referenciais de masculinidade (Andrade et al., 2015), quanto o imperativo atual de se discutir as estratégias de contenção da epidemia de HIV entre mulheres, em estreita relação ao aumento da violência contra elas em todo o mundo (Unaids, 2019b).

b) Percepção sobre o preservativo e sua utilização: Nesta categoria busca-se apresentar e discutir as principais percepções sobre o preservativo masculino e seu uso: prevenção da gravidez; prevenção de IST e interferência no prazer. É possível observar que a suposição de confiança no parceiro, discutida na categoria anterior, também apareceu na discussão desses temas. O preservativo feminino não apareceu em nenhum momento na fala dos participantes ao longo das rodas de conversa desenvolvidas.

Chama a atenção que tanto mulheres quanto homens mencionaram o uso do preservativo vinculado à função prioritária de método anticoncepcional e poucas vezes se referem a ele como fator de proteção às IST/aids. Além disso, a preferência pelo uso de anticoncepcional aparece como forma de evitar o preservativo e manter o prazer, uma vez que há uma clara associação entre uso do preservativo e diminuição do prazer sexual.

\begin{abstract}
"Se não fosse caso de gestação ou por não tomar anticoncepcional não usaria porque acho que por ser casada não precisa de usar. Vai na questão da confiança." (S28, F, 31, EF)

"Nunca usei camisinha então não sei dizer se interfere no prazer. Nunca usei porque não tive vontade. Uso o DIU." (S35, F, 44, EF)

"Eu usava camisinha para evitar filhos." (S61, F, 30, ES)

"Só uso quando esqueci o comprimido." (S78, F, 32, EM)

"Na hora do vamos ver, é bom usar o anticoncepcional, pois chupar bala com papel é a coisa mais difícil e pior que tem." (S128, M, 19, EF)
\end{abstract}

A literatura científica demonstra que, apesar de homens e mulheres conhecerem o papel do preservativo na prevenção de IST, vários aspectos dificultam o seu uso, entre eles, a ideia de que o preservativo é apenas como método contraceptivo; a percepção de que ele interfere no prazer; a faixa etária; o tempo de relacionamento e o tipo de relação afetivo-sexual a qual os parceiros estão vinculados. (Andrade et. al., 2015; Gutierrez et. al., 2019; Pereira, Schmitt, Cardoso, \& Aldrighi, 2008; Silva, 2012). As associações entre uso do preservativo e diminuição da sensibilidade e do prazer, também foram apontadas pelos participantes:

\footnotetext{
"Não quero usar, é como chupar bala com plástico. Muito melhor fazer sexo sem camisinha, é mais prazeroso." (S14, F, 27, ESI)
}

"Na hora do sexo oral quase ninguém usa camisinha porque o gosto é ruim. (S28, F, 31, EF)

É chupar bala com papel - meu marido fala, pra mulher é a mesma coisa, com ou sem é igual." (S91, F, 29, EF)

Eu não gosto. Se for para escolher ou ficar sem a camisinha eu prefiro ficar sem. (S124, M, 18, EF)

No entanto, estão presentes também, em menor quantidade as discussões sobre a necessidade de usar preservativo como forma de prevenção de IST.

"Na sexualidade, as DST, o que previne é a camisinha, apesar da gente não gostar tem que usar. Camisinha incomoda um pouco." (S147, F, 23, EM) 
"Eu acho que perde a sensibilidade, mas quem não tem só um parceiro tem que usar." (S106, M, 18, EF)

A dificuldade em relação ao uso de preservativo vem sendo registrada em diferentes estudos, seja por alegação de interferência no prazer, baixa percepção de risco que o uso inconsistente do preservativo pode trazer, e também pela inconsistência em relação aos conhecimentos e práticas em relação ao seu uso (Andrade et al, 2015; Rivemales, 2009).

c) Conhecimentos sobre preservativos e IST/aids e as mudanças de comportamento e percepções relacionadas às práticas sexuais: Esta categoria busca apresentar e discutir a relação entre conhecimentos anunciados pelos participantes sobre uso de preservativo e prevenção de IST/aids e as mudanças de comportamento em relação às práticas sexuais e a percepção do risco.

Mudanças de comportamento não dependem exclusivamente de acesso às informações. Parece ser um equívoco supor que seria possível mudar as práticas sexuais considerando apenas a apresentação das informações sobre prevenção de IST e riscos em saúde a partir de relações desprotegidas, uma vez que existem outros fatores da biografia sexual de cada indivíduo que interferem na adoção de medidas preventivas (Aboim, 2012). Nesse sentido, é fundamental levar em consideração as críticas que vêm sendo feitas à adoção de modelos de educação em saúde que não consideram diferenças antropológicas e sociológicas envolvidas na prevenção e promoção de saúde. (Parker \& Camargo Jr., 2000). As práticas de educação em saúde não podem se basear no repasse de informações e sim na possibilidade de construção de espaços de diálogo nos quais o conhecimento em saúde entra como um elemento num processo mais amplo de reflexão dos sujeitos em seus contextos e realidades específicas.

Para além dos modos de abordar os sujeitos nas ações educativas é preciso considerar as influências do contexto-sócio-cultural necessário para produzir práticas preventivas e as condições relacionadas à produção de sentido, individual e coletivamente. Nesse sentido, a construção de conhecimento pautada nesses aspectos está ancorada em uma posição ético-político que permite refletir, por exemplo, nos desafios a serem enfrentados pela promoção de saúde e prevenção das IST/aids no atual contexto de retrocessos e abandono das experiências exitosas no combate à aids no Brasil, que se pautou até então, nas relações entre prevenção e desigualdades de gênero, sexualidade; direitos humanos, estigmas e, homossexualidade e os investimentos em formas não medicamentosas de prevenção (Seffner \& Parker, 2016)

As falas a seguir demonstram a complexidade entre conhecimento e mudança de comportamento:

"Não uso preservativo. Não vai acontecer nada comigo eu acho." (S17, F, 20, ESI)

"Informação nós temos de sobra. Nós não a usamos; não colocamos em prática." (S70, F, 42, ES)

"Se pegasse DST por falta de informação, não existiria entre os profissionais de saúde. A questão é como essa informação vai virar ação." (S71, F, 34, ES)

"Acho que informação eles têm. Talvez seja por inconsequência, não sei. Por inconsequência, uso do álcool... vai e faz, mesmo tendo informação. O idoso tem mais resistência." (S23, F, 38, ESI)

Diante das dificuldades levantadas pelos participantes das rodas de conversa sobre o uso do preservativo, observa-se um descompasso ou incoerência entre os conhecimentos expressos pelos mesmos sobre os riscos de se contrair uma IST e a adoção de práticas sexuais protegidas por preservativos. Esse descompasso ou incoerência vem sendo observado e discutido em outros estudos que apontam que homens e mulheres de diferentes faixas etárias relatam conhecer o preservativo como método eficaz de prevenção das IST/aids, não necessariamente utilizam o preservativo como uma prática de prevenção (Aboim, 2012; Andrade et al., 2015, Gutierrez et. al., 2019). Além disso, estudos apontam a presença de estereótipos e preconceitos presentes na sociedade que sustentam a permanência da ideia de que as IST/aids seriam questões exclusivas de alguns grupos populacionais específicos (Aboim, 2012; Manuel, 2009; Rodrigues et al., 2012; Silva, 2012), o que também pode contribuir para o conjunto de dificuldades relacionadas ao uso de preservativo masculino, a percepção de risco e a adoção de medidas de prevenção e proteção às IST/aids.

Nas falas dos participantes está presente também a falta de conhecimento ou conhecimento inconsistente sobre IST, levando inclusive a uma banalização sobre as doenças:

"Quanto à doença, HIV, não tem cura, mas tem tratamento, prefiro correr o risco." (S25, F, 21, ESI).

"Vasectomia previne doença." (S76, M, 27, EM)

"DST... eu só conheço a aids". (S124, M, 18, EF) 
Apesar da importância da divulgação de informações a respeito de IST/aids, não se pode desconsiderar o antagonismo entre conhecimento e as práticas sexuais, e de que forma tais questões podem se relacionar às dificuldades de uso do preservativo (Gutierrez et. al., 2019) Nesse sentido, o profissional de saúde e as ações de educação em saúde devem analisar os diferentes modelos de abordagem da sexualidade, das práticas sexuais e de formas de prevenção para saber em que medida se restringem a um enfoque biológico de regulação e tutela sobre os corpos e os comportamentos ou se conseguem abarcar aspectos psicossociais que englobem dimensões socioculturais e subjetivas (Vieira \& Matsukura, 2017).

\section{Considerações finais}

Pensar em prevenção efetiva requer que se abordem as relações entre as pessoas, o vírus HIV e as diferentes tecnologias e insumos preventivos, tanto de caráter biomédico quanto comportamental e estrutural. Toda prevenção demanda que práticas sociais sejam mudadas, e tais mudanças não podem se sustentar a menos que se apoiem em transformações sociais amplas, que envolvam diálogo sobre temas tabus, estigmas, preconceitos, avanços e retrocessos em termos de políticas públicas que necessariamente fazem interface com estas questões. É necessário, para tanto, que se entenda que a sexualidade é um tema permeado por valores, culturas e desigualdades, e seu debate deve envolver questões de gênero, identidade e orientação sexual, de forma que a singularidade e a diversidade das pessoas sejam acolhidas.

O preservativo masculino é uma tecnologia biomédica, com importância considerável na prevenção da epidemia de HIV/aids e de outras IST e que representa um recurso cuja utilização está associada a representações culturais diversas. É imperativo, portanto, não apenas sua ampla distribuição, mas a abordagem das questões que estão associadas a seu uso. Considerando que os resultados deste estudo demonstram a persistência da dificuldade de homens e mulheres na utilização do preservativo nas práticas sexuais, torna-se importante ampliar nossa compreensão acerca dos motivos relacionados a essas dificuldades e formas de que esses conhecimentos produzidos se repercutam nas práticas de educação em saúde.

No atual contexto de preocupações em relação aos retrocessos nas políticas de prevenção de IST/aids, ressalta-se a importância das metodologias de educação em saúde que coloquem os sujeitos como participantes da construção do seu próprio saber e que se constituam como estratégias flexíveis e sensíveis às diferenças individuais e grupais no contexto das desigualdades socioeconômicas, de poder, de gênero e etnia. Nesse sentido, para além de pautas religiosas ou conservadoras que perpetuam estigmas e preconceitos, as ações de educação em saúde devem se pautar em relações mais solidárias e propiciar aos sujeitos e grupos a construção de sentidos voltados para a vida, para a cidadania, para a construção de autonomia e para a adoção de comportamentos favoráveis à promoção de saúde.

\section{Referências}

Aboim, S. (2012). Risco e prevenção do HIV/Aids: uma perspectiva biográfica sobre os comportamentos sexuais em Portugal. Ciência \& Saúde Coletiva, 17(1), 99-112. doi: 10.1590/ S1413-81232012000100013

Adamy, P. E., Casimiro, G., \& Benzaken, A. (2018). Na era da prevenção combinada. In V. Leite, V. Terto Jr., \& R. Parker (Orgs.), Dimensões sociais e políticas da prevenção (pp. 29-34). Rio de Janeiro: Associação Brasileira Interdisciplinar de AIDS. Recuperado de http://abiaids.org.br/ dimensoes-sociais-e-politicas-da-prevencao/32257

Afonso, M. L. M. (2006). (Org.). Oficinas em dinâmica de grupo na área da saúde. São Paulo: Casa do Psicólogo.

Afonso, M. L. M., \& Abade, F. (2008). Para reinventar as Rodas. Belo Horizonte: Rede de Cidadania Mateus Afonso Medeiros (RECIMAM)

Andrade, S. S. C., Zaccara, A. A. L., Leite, K. N. S., Brito, K. K. G., Soares, M. J. G. O., Costa, M. M. L., ... Oliveira, S. H. S. (2015). Conhecimento, atitude e prática de mulheres de um aglomerado subnormal sobre preservativos. Revista da Escola de Enfermagem da USP, 49(3), 364-372. doi: 10.1590/S0080-623420150000300002

Antunes, M. C., Peres, C. A., Paiva, V., Stall, R., \& Hearst, N. A. (2002). Diferenças na prevenção da Aids entre homens e mulheres jovens de escolas públicas em São Paulo, SP. Revista Saúde Pública, 36(Suppl. 4 ), 88-95. doi: 10.1590/S0034-89102002000500013

Ayres, J. R. C. M. (2002). Práticas educativas e prevenção de HIV/Aids: lições aprendidas e desafios atuais. Interface - Comunicação, Saúde, Educação, 6(11), 11-24. Recuperado de http://www.scielo.br/pdf/icse/ v6n11/01.pdf

Bacchini, A. M. (2017). Faz-se tudo por amor, inclusive "morre-se": o ideal de amor romântico e a exposição de mulheres ao hiv/AIDS (Tese de doutorado, Departamento de Psicologia, Pontifícia Universidade Católica do Rio de Janeiro). Rio de Janeiro. Recuperado de http://www2.dbd.puc-rio.br/pergamum/ tesesabertas/1311622_2017_completo.pdf

Bardin, L. (2011). Análise de conteúdo (L. de A. Rego \& A. Pinheiro, Trads.). Lisboa: Edições 70. (Obra original publicada em 1977)

Decreto n. № 9.795. (2019, 17 de Maio). Aprova a estrutura regimental e o quadro demonstrativo dos cargos em comissão e das funções de confiança do Ministério da Saúde, remaneja cargos em comissão e funções de confiança, transforma funções de confiança e substitui cargos em comissão do grupo-direção e assessoramento superiores 
- das por funções comissionadas do Poder Executivo - FCPE. Brasília, DF: Presidência da República.

Emenda Constitucional no 95. (2016, 15 de Dezembro). Altera o ato das disposições constitucionais transitórias, para instituir o novo regime fiscal, e dá outras providências. Brasília, DF: Presidência da República.

Freire, P. (2002). Educação como prática da liberdade. São Paulo: Paze Terra.

Goulart, I. B. (2002). Psicologia Organizacional e do Trabalho; teoria, pesquisa e temas correlatos. São Paulo: Casa do psicólogo.

Gutierrez, E. B., Pinto, V. M., Basso, C. R., Spiassi, A. L., Lopes, M. E. B. R., \& Barros, C. R. S. (2019). Fatores associados ao uso de preservativo em jovens - inquérito de base populacional. Revista Brasileira de Epidemiologia, 22, e190034. Epub Abr 25. doi: 10.1590/1980-549720190034

Jewkes, R. (2010). Gender inequities must be addressed in HIV prevention. Science, New Series, 329(5988), 145-147. Recuperado de http://www.jstor.org/stable/40731917

Joint United Nations Programme on HIV/AIDS. (2010). Combination HIV prevention: tailoring and coordinating biomedical, behavioural and structural strategies to reduce new HIV Infections. Genebra: World Health Organization. Recuperado de https://www.unaids.org/ sites/default/files/media_asset/JC2007_Combination_Prevention_ paper_en_0.pdf

Joint United Nations Programme on HIV/AIDS. (2016). Global report: UNAIDS report on the global AIDS epidemic. Genebra:World Health Organization. Recuperado de http://www.unaids.org/sites/default/ files/media_asset/global-AIDS-update-2016_en.pdf

Joint United Nations Programme on HIV/AIDS. (2019a). Communities at the Centre. Genebra: World Health Organization. Recuperado de https://www.unaids.org/en/20190716_GR2019_communities

Joint United Nations Programme on HIV/AIDS. (2019b). 19.6 million girls and women living with HIV. Recuperado de https://www.unaids.org/ en/resources/infographics/girls-and-women-living-with-HIV

Knauth, D. R., Víctora, C. G., \& Leal, O. F. (1998). A banalização da Aids. Horizontes Antropológicos, 4(9), 171-202. doi: 10.1590/ S0104-71831998000200010

Lindenmeyer, C., \& Ceccarelli, P. R. (2012). O pensamento mágico na constituição do psiquismo. Reverso, 34(63), 45-52. Recuperado de http://pepsic.bvsalud.org/scielo. php?script=sci_arttext\&pid=S0102-73952012000200005\&lng=pt \&tlng $=\mathrm{pt}$

Manuel, S. (2009). Presentes perigosos: dinâmicas de risco de infecção ao HIV/Aids nos relacionamentos de namoro em Maputo. Physis: Revista de Saúde Coletiva, 19(2), 371-386. doi: 10.1590/ S0103-73312009000200007

Marafon, G. (2018). Análises críticas para desmontar o termo "ideologia de gênero". Arquivos Brasileiros de Psicologia, 70(spe.), 117-131. Recuperado de https://pesquisa.bvsalud.org/portal/resource/pt/ biblio-987352

Minayo, M. C. S. (2008). O desafio do conhecimento. Pesquisa qualitativa

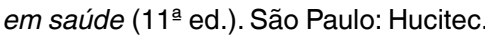

Ministério da Saúde. (2018a). Secretaria de Vigilância em Saúde, Departamento de Vigilância, Prevenção e Controle das IST, do HIV/Aids e das Hepatites Virais. Relatório de Monitoramento Clínico do HIV. Brasília, DF: Ministério da Saúde. Recuperado de http://www.aids.gov.br/pt-br/pub/2018/ relatorio-de-monitoramento-clinico-do-hiv-2018
Ministério da Saúde. (2018b). Secretaria de Vigilância em Saúde, Departamento de Vigilância, Prevenção e Controle das IST, do HIV/ Aids e das Hepatites Virais. Boletim Epidemiológico HIV/AIDS 2018. Brasília, DF. Ministério da Saúde. Recuperado de http://www.aids. gov.br/pt-br/pub/2017/boletim-epidemiologico-hivaids-2018

Nogueira, V. M. R., \& Pires, D. E. P. (2004). Direito à saúde: um convite à reflexão. Cadernos de Saúde Pública, 20(3), 753-760. doi: 10.1590/ S0102-311X2004000300012

Noronha, J. C., Noronha, G. S., Pereira, T. R., \& Costa, A. M. (2018) Notas sobre o futuro do SUS: breve exame de caminhos e descaminhos trilhados em um horizonte de incertezas e desalentos. Ciência \& Saúde Coletiva, 23(6), 2051-2059. doi: 10.1590/1413-81232018236.05732018

Paiva, M. S. (1999). A feminilização da AIDS: uma questão de gênero? Revista Brasileira de Enfermagem, 52(1), 7-13. doi: 10.1590/ S0034-71671999000100002

Parker, R. (2015, 24 de setembro). O fim da Aids. Recuperado de http://abiaids.org.br/o-fim-daaids/28618

Parker, R., \& Camargo Jr., K. R. (2000). Pobreza e HIV/AIDS: aspectos antropológicos e sociológicos. Cadernos de Saúde Pública, 16(Suppl.1), S89-S102. doi:10.1590/S0102-311X2000000700008

Pereira, E. C. A., Schmitt, A. C., Cardoso, M. R. A., \& Aldrighi, J. M. (2008). Tendência da incidência e da mortalidade por AIDS em mulheres na transição menopausal e pós-menopausa no Brasil, 1996-2005. Revista da Associação Médica Brasileira, 54(5), 422-425. doi: 10.1590/S0104-42302008000500015

Política de morte: o fim do departamento de AIDS. (2019, 22 de maio) Recuperado de http://abiaids.org.br/politica-de-morte-o-fimdo-departamento-de-aids/32852

Rios, R. R. (2018). Políticas públicas de saúde e prevenção como direito. In V. Leite, V. Terto Jr., \& R. Parker (Orgs.), Dimensões sociais e políticas da prevenção (pp. 29-34). Rio de Janeiro: Associação Brasileira Interdisciplinar de AIDS. Recuperado de http://abiaids. org.br/dimensoes-sociais-e-politicas-da-prevencao/32257

Rivemales, M. C. C., Almeida, G. M., \& Queiroz, M. M. A. (2009). Adesão de mulheres ao uso do preservativo em um programa de planejamento familiar de Salvador, Bahia. Revista de Enfermagem UFPE, 3(1). Recuperado de http://www.revista.ufpe.br/revistaenfermagem/index. php/revista/article/viewArticle/262

Rodrigues, L. S. A., Paiva, M. S.; Oliveira, J. F., \& Nóbrega, S. M. (2012). Vulnerabilidade de mulheres em união heterossexual estável à infecção pelo HIV/Aids: estudo de representações sociais. Revista da Escola de Enfermagem da USP, 46(2), 349-355. Recuperado de http://www.scielo.br/pdf/reeusp/v46n2/a12v46n2.pdf

Secretaria Geral da Presidência da República. (2014). Marco de referência da educação popular para as políticas públicas. Brasília, DF: Departamento de Educação Popular e Mobilização Cidadã e Grupo de Trabalho da Política Nacional de Educação. Recuperado de http://conae2014.mec.gov.br/images/pdf/MarcodeReferencia.pdf

Seffner, F., \& Parker, R. (2016). Desperdício da experiência e precarização da vida: momento político contemporâneo da resposta brasileira à AIDS. Interface, 20(57), 293-304. doi: 10.1590/1807-57622015.0459

Silva, G. A., \& Reis, V.N. (2012). Construindo caminhos de conhecimentos em HIV/Aids: mulheres em cena. Physis: Revista de Saúde Coletiva, 22(4), 1439-1458. doi: 10.1590/S0103-73312012000400010

Souza, A. A., \& Cadete, M. M. M. (2017). Roda de conversa: ferramenta pedagógica para a compreensão dos problemas alimentares contemporâneos. Contribuciones a las Ciencias Sociales, (abril-junho

Estudos de Psicologia, 24(1), janeiro a março de 2019, 21-31 
de 2017). Recuperado de http://www.eumed.net/rev/cccss/2017/02/ roda-conversa.html

The Foundation for AIDS Research. (2015). Women and HIVIAIDS worldwide: Fast-tracking the end of an epidemic. Washington, DC: The Foundation for Aids Research. Recuperado de https://www.amfar. org/uploadedFiles/_amfarorg/Articles/On_The_Hill/2015/IB_WomenHIV_Worldwide_2015-03-19_FINAL.pdf
Tura, L. F. R. (2005). A Aids: repensando a prevenção. In L. F. R. Tura \& A S. P. Moreira (Orgs.), Saúde e representações sociais (pp. 167-190). João Pessoa: EdUFPB

Vieira, P. M., \& Matsukura, T.S. (2017). Modelos de educação sexual na escola: concepções e práticas de professores do ensino fundamental da rede pública. Revista Brasileira de Educação, 69(22), 453-474 doi: 10.1590/s1413-24782017226923

Denise Alves Guimarães, doutora em Psicologia Social pela Pontifícia Universidade Católica de São Paulo - PUC-SP, é professora da Universidade Federal de São João del Rei, Campus Centro-Oeste UFSJ/CCO. Endereço para correspondência: Avenida Sebastião Gonçalves Coelho, 400, Bairro Chanadour - Divinópolis/MG. CEP - 35.501-296. COMED Coordenadoria do Curso de Medicina do CCO.

E-mail: alvesguimaraesdenise@gmail.com

Vanessa Cristina de Paiva Oliveira, é graduanda do curso de Medicina, Universidade Federal de São João del Rei,

Campus Centro Oeste/UFSJ-CCO. E-mail: vanessacpoli@gmail.com

Leandro Cesar da Silva, graduado em medicina pela Universidade Federal de São João del Rei, Campus Centro Oeste/UFSJ-CCO, é médico infectologista, Hospital MedCenter Patrocínio-MG. E-mail: leandro.css@hotmail.com

Cândida Amélia Marinho de Oliveira, graduada em medicina pela Universidade Federal de São João Del-Rei - Campus Centro-Oeste

Dona Lindu (UFSJ - CCO), é médica residente em Obstetrícia e Ginecologia na Maternidade Odete Valadares-MG. E-mail: candyamelia2004@yahoo.com.br

Rânia Andrade Lima, graduada em medicina pela Universidade Federal de São João del Rei, Campus Centro Oeste/UFSJ-CCO, é residente em clínica médica pelo Hospital Fundação Ouro Branco (FOB)-MG. E-mail: ranialima@yahoo.com.br

Carlos Alberto Pegolo da Gama, doutor em saúde coletiva pela Universidade Estadual de Campinas, pós-Doutor em saúde coletiva pela Université Paris 13 - Bobigny, PARIS 13, França, é professor ddjunto da Universidade Federal de São João Del Rei, Campus Centro Oeste/UFSJ-CCO. E-mail: carlosgama@terra.com.br

Recebido em 27.mai.18 Aceito em 29.set.19 Revisado em 21.out.19 